\title{
TRPV1 Channel: A Noxious Signal Transducer That Affects Mitochondrial Function
}

\author{
Rebeca Juárez-Contreras ${ }^{1}$, Karina Angélica Méndez-Reséndiz ${ }^{1}$, Tamara Rosenbaum ${ }^{1}{ }^{1}$, \\ Ricardo González-Ramírez ${ }^{2}$ (1) and Sara Luz Morales-Lázaro ${ }^{1, *}$ \\ 1 Department of Cognitive Neuroscience, Neurosciences Division, Institute of Cellular Physiology, \\ National Autonomous University of Mexico, UNAM, Mexico City 04510, Mexico; \\ rjuarez@ifc.unam.mx (R.J.-C.); amendez@ifc.unam.mx (K.A.M.-R.); trosenba@ifc.unam.mx (T.R.) \\ 2 Department of Molecular Biology and Histocompatibility, "Dr. Manuel Gea González" General Hospital, \\ Mexico City 14080, Mexico; ricardo.gonzalezr@salud.gob.mx \\ * Correspondence: saraluzm@ifc.unam.mx
}

Received: 30 September 2020; Accepted: 31 October 2020; Published: 24 November 2020

check for updates

\begin{abstract}
The Transient Receptor Vanilloid 1 (TRPV1) or capsaicin receptor is a nonselective cation channel, which is abundantly expressed in nociceptors. This channel is an important transducer of several noxious stimuli, having a pivotal role in pain development. Several TRPV1 studies have focused on understanding its structure and function, as well as on the identification of compounds that regulate its activity. The intracellular roles of these channels have also been explored, highlighting TRPV1's actions in the homeostasis of $\mathrm{Ca}^{2+}$ in organelles such as the mitochondria. These studies have evidenced how the activation of TRPV1 affects mitochondrial functions and how this organelle can regulate TRPV1-mediated nociception. The close relationship between this channel and mitochondria has been determined in neuronal and non-neuronal cells, demonstrating that TRPV1 activation strongly impacts on cell physiology. This review focuses on describing experimental evidence showing that TRPV1 influences mitochondrial function.
\end{abstract}

Keywords: TRPV1; nociception; mitochondrial dysfunction; ROS; apoptosis; pain

\section{Introduction}

The interpretation of the cell's environmental signals depends upon transducing and encoding these stimuli into a comprehensible cellular language. This selective process is facilitated by several ion channels located in the cell's plasma membrane, among which the family of transient receptor potential (TRP) cation channels plays an essential role.

The first evidence for the existence of these channels was found in the Drosophila melanogaster fly. Cosens and Manning [1] analyzed a spontaneous mutant that displayed transient rather than sustained responses in the presence of prolonged bright illumination in electroretinogram (ERG) measurements [1]. This mutation rendered the flies blind and the investigators who isolated this mutant named it the "A-type" mutant, ascribing its phenotype to a failure of photopigment regeneration [2]. Nonetheless, several concerns were raised at the time of its isolation, with the main one being that the results were based on a single spontaneously occurring mutant, for which there was no description of its genetic background. Hence, there was a lack of knowledge on what genetic alterations this strain embodied with the results possibly being due to the additive effects of alterations in several genes mapping to the same chromosome [3]. Pak and collaborators proved that the observed phenotype was indeed due to mutation in a single gene by isolating multiple mutated alleles from a baseline stock of known genetic background [3]. It was also important to establish the cellular origins of the measured ERG components because it had not been determined whether the lack of a sustained response seen 
in the ERG of this strain originated from the photoreceptors or from other retinal cells [3]. In 1975, Minke and collaborators performed intracellular recordings from the mutant photoreceptors and were able to determine that the defect arose from the photoreceptors. Thus, they concluded that this mutant is defective in phototransduction [4]. Several other studies were performed with this mutant, which helped to forge a representative name for this mutant: the "transient receptor potential" or TRP [4-6].

Ten years later, the trp gene was isolated [7] and characterized as a genomic region that encodes for some RNA species missing in the mutant fly [8]. Interestingly, transformation of the mutant germline with the region encoding for the trp gene reestablished the normal phototransduction phenotype in the trp mutant fly, confirming the identity of this gene [7]. Finally, the cloning of the trp gene suggested a transmembrane protein with eight $\alpha$-helices containing highly hydrophilic $\mathrm{N}$ - and $\mathrm{C}$-termini, which was consistent with already known receptor/transporter/channel proteins $[9,10]$.

The TRP protein was localized to the rhabdomere, and hence thought to participate in phototransduction. Nonetheless, the absence of homologous proteins to the TRP in available databases and other results suggested that in null trp alleles, there was still a persistent sustained receptor potential under dim light stimulation $[4,11]$ and so it was concluded that the trp gene does not encode for the light-sensitive channel $[9,10]$.

Later, it was shown that $\mathrm{La}^{3+}$ could mimic the trp phenotype [12], and this led to the proposal that the trp gene encoded for an inositide-activated $\mathrm{Ca}^{2+}$ channel/transporter required for $\mathrm{Ca}^{2+}$ store refilling [13]. Voltage-clamp recording in the whole-cell configuration showed that the primary defect in the trp mutant was a drastic reduction in the $\mathrm{Ca}^{2+}$ permeability of the light-sensitive channels themselves [14].

Then, another protein similar to the trp gene product was found, the TRP-like (TRPL) [15]. The product encoded by the trpl gene exhibited characteristics of a transmembrane protein that contains two putative calmodulin-binding sites and an ankyrin-like repeat domain [15]. Sequence homology analyses demonstrated that the central transmembrane region of the trp and trpl products resemble the transmembrane segments (S1-S6) of calcium channels, suggesting that these TRP proteins could act as ion channels [15]. The functional description of invertebrate TRP proteins demonstrated that these proteins function as light-sensitive ion channels that allow calcium entry in Drosophila photoreceptors [14], and the phenotype of the trp mutation was reinterpreted and it was suggested that the light response of Drosophila is mediated by channels composed from the trp and trpl gene products $[14,15]$. In summary, there are two distinct conductances that give rise to the normal light-sensitive current: one encoded by the trp gene that is highly $\mathrm{Ca}^{2+}$ selective, and a second channel that is responsible for the residual light-sensitive current in the trp mutants encoded by the homologous gene trpl.

Remarkably, the trp/trpl gene products lack the presence of several positively-charged amino acids in their S4, the region that typically constitutes the voltage sensor in $\mathrm{Ca}^{2+}$ channels, suggesting that these invertebrate TRP proteins lack this domain. These features were the first clues about the structure of invertebrate proteins belonging to the TRP family of ion channels.

Later, these structural characteristics were identified in the first mammalian homolog of the TRP gene isolated from human fetal brain cDNA libraries. It was named the transient receptor potential channel-related 1 (TRPC1), a protein with similar structural organization to that of TRP proteins from invertebrates [16]. This, in turn, led to the isolation and characterization of several TRP channels, resulting in discoveries pertaining to their pivotal roles in mammalian physiology.

To date, TRP channels represent an extended and essential family of ion channels composed of 28 members divided according to homology in their primary sequences. This family is classified into seven subfamilies: TRPC (canonical), TRPV (vanilloid), TRPM (melastatin), TRPP (polycystin), TRPML (mucolipin), TRPA (ankyrin) and TRPN (no mechanoreceptor), and the latter is exclusively found in invertebrates and fish [17] (Figure 1). Additionally, another subfamily called TRPY (yeast) has 
been identified in vacuoles from Saccharomyces cerevisiae [18], although the details of its physiological roles remain unknown.

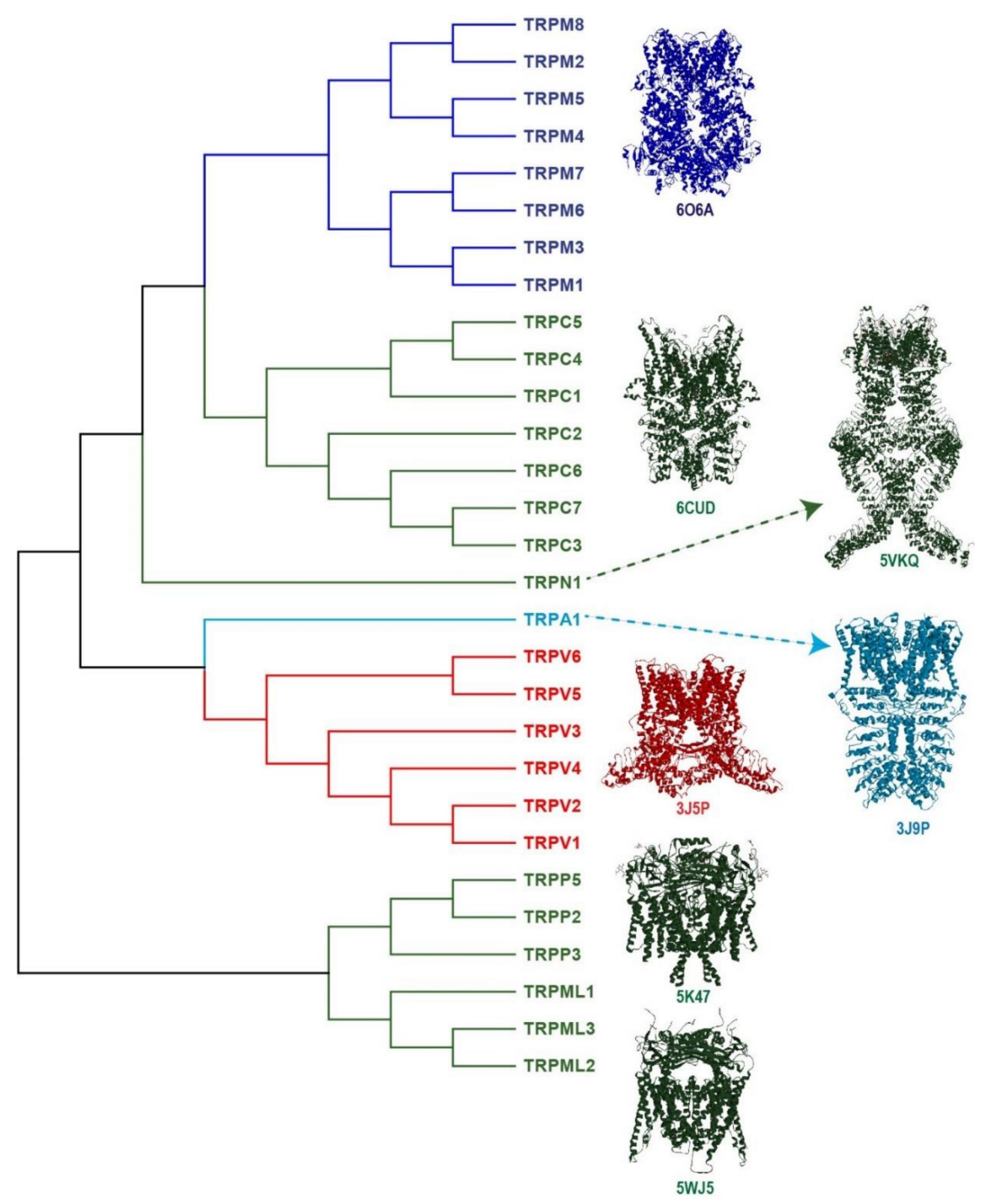

Figure 1. The Transient Receptor Potential (TRP) superfamily of ion channels. TRP ion channels are classified into seven subfamilies: TRPC (canonical), TRPV (vanilloid), TRPM (melastatin), TRPP (polycystin), TRPML (mucolipin), TRPA1 (ankyrin) and TRPN (no mechanoreceptor). The figure shows the phylogenetic analysis between the human TRP protein sequences; the alignment was obtained using ClustalW2 at the EMBL-EBI server. For TRPC2 (pseudogene) and TRPN (not expressed in humans), the sequences used were from mice and fish, respectively. The channels colored in dark-, light-blue and red refer to some of the channels known as the thermo-TRP, since there are activated by cool, cold and hot temperatures (TRPM81, TRPA1 and TRPV1, respectively). The figure also shows the tetrameric 3D-structure of a representative member of each subfamily. TRPM8 (6O6A), TRPC3 (6CUD), TRPN (5VKQ), TRPA1 (3J9P), TRPV1 (3J5P) TRPP2 (5K47) and TRPML1 (5WJ5). The symbols beneath each 3D-structure are the number access in the Protein Data Bank (PDB).

Interestingly, TRP channel localization and function are not limited to the cell surface. Some of these channels are intracellularly located in the membranes of organelles, regulating ion flux between 
the cytosol and these intracellular compartments [19,20]; furthermore, cell surface-located channels can also regulate calcium homeostasis in some organelles, such as the mitochondria. In this review, we will describe how TRPV1 activation modifies mitochondrial function. Here, we will discuss the data showing that the channel's activation can induce mitochondrial dysfunction in neuronal and non-neuronal cells.

\section{The TRPV1 Channel: A Key Transducer of Nociception}

The discovery of the TRP channel, known as the "capsaicin" receptor or TRPV1, highlighted its essential role in mammalian nociception [21-23]. Its isolation and cloning represented a significant step in the advancement of the pain research field, providing initial evidence of the relationship between the structure, the activity, and the physiological role of this channel [21-23].

TRPV1 cDNA was isolated from a rodent dorsal root ganglion (DRG) library and expressed in oocytes to perform membrane recordings, confirming that capsaicin evokes currents through the activation of this channel [22]. Full characterization of the activity and properties of TRPV1 showed that it is a nonselective cation channel which exhibits preference to $\mathrm{Ca}^{2+}$ ions [22].

The TRPV1 protein is abundantly expressed in small and medium diameter sensory neurons from trigeminal and dorsal root ganglia (TG and DRG, respectively), as well as in the nodose ganglia [22-24]. Its expression is mainly associated with Substance P-producing DRG neurons, which are widely related to pain perception [23]. Additionally, low TRPV1 expression has been reported in specific regions of the central nervous system, and in non-neuronal cells [25-27], where elucidation of its roles in these areas has been extensively studied.

Additionally, it was demonstrated that natural compounds activate the polymodal TRPV1 channel. Examples of these compounds are capsaicin, resiniferatoxin and allicin (the pungent compound of chili peppers and chemical compounds found in Euphorbia resinifera and garlic, respectively) [22,28]. Also, TRPV1 is activated by noxious heat (around $42{ }^{\circ} \mathrm{C}$ ) and by extracellular acid and basic intracellular $\mathrm{pH}[22,23,29]$. Furthermore, TRPV1 is activated by some endogenous compounds, such as anandamide, lysophosphatidic acid (LPA), and by metabolites derived from arachidonic acid and linoleic acid byproducts, among others [30-33].

Transgenic mice lacking TRPV1 expression (TRPV1-KO) evidenced that this channel is a crucial transducer of several noxious signals that converge to integrate painful stimuli, since these mice display impaired nociception [21].

Until now, several reports support the essential role of TRPV1 modulation through modifications such as phosphorylation, which is associated with lowering the activation threshold, usually referred as sensitization [34]. In contrast, dephosphorylation or reduction of the channels available on the cell surface causes desensitization $[35,36]$. These phenomena are crucial in hyperalgesia and chronic pain events, where inflammatory molecules sensitize TRPV1 [37].

\subsection{TRPV1 Structural Features}

Prediction of the TRPV1 protein structure suggested it was a protein containing six transmembrane segments (S1-S6) joined by intracellular and extracellular loops [22], where the re-entrant loop between S5 and S6 form the pore or ion conduction pathway when the channel is assembled as a homotetramer (Figure 2a). 


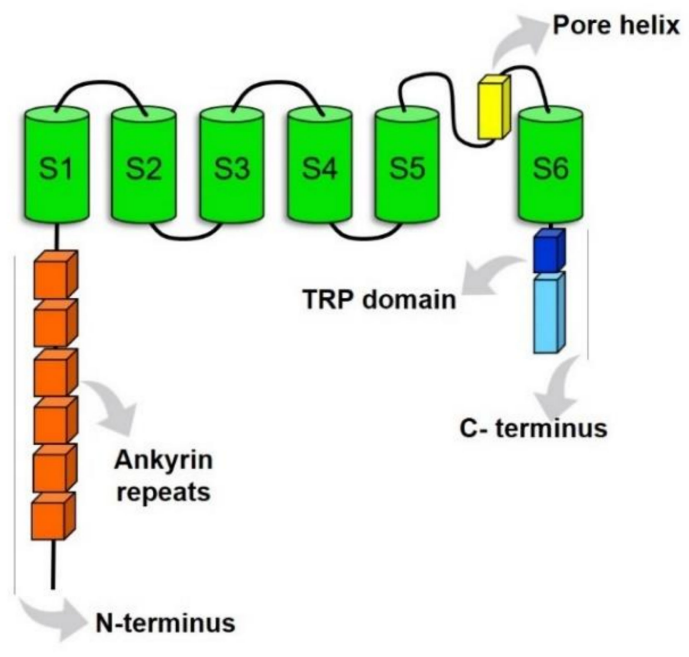

(a)

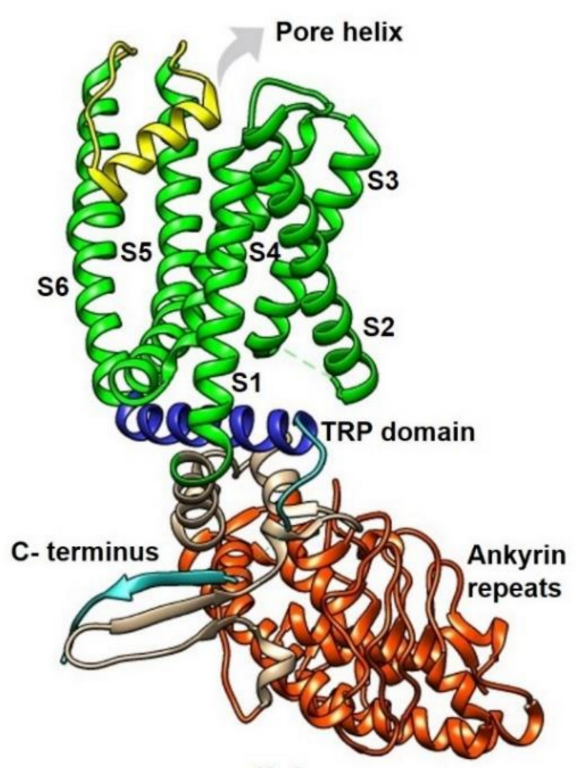

(b)

Figure 2. Structural features of the TRPV1 protein. (a) This figure schematizes the domains of a TRPV1 monomer (or subunit). The amino- and carboxy- termini are intracellularly located (N- and Ctermini), the six ankyrin repeats and the TRP-box are contained in the $\mathrm{N}$ - and C-termini, respectively. The re-entrant loop between the S5-S6 forms the ionic conduction pore when the tetramer is formed. (b) 3D-representation of a TRPV1 subunit displaying the arrangement of the domains represented in (a). S1-S6: transmembrane segments.

The first 3D structural details of TRPV1 were obtained using X-ray crystallographic techniques [38]. These assays confirmed the presence of a domain with six ankyrin repeats (ARD), each consisting of a pair of antiparallel $\alpha$-helices linked by a finger loop. Functionally, these ankyrin repeats have an important role for the interaction between ATP and calmodulin (CaM) [38]. Additionally, a CaM binding site located in the C-terminal region of TRPV1 was also described $[39,40]$, suggesting that CaM plays a critical role in TRPV1 modulation.

A few years later, single-particle electron cryo-microscopy (cryo-EM) allowed for the solving of the first TRPV1 three-dimensional (3D) structure at a low resolution (19 $\AA$ ) [41]. This structure confirmed the tetrameric channel conformation with a large open basket-like domain corresponding to the intracellular N- and C-termini, and a compact transmembrane domain that resembles that of the transmembrane domain structure of voltage-gated potassium (Kv) and sodium (Nav) channels [41]. TRP channels in general resemble voltage-gated ion channels. They display reminiscent structural features such as the presence of an antiparallel $\beta$-sheet from the linker region and a $\beta$-strand from the C-terminus region that make contact with two of the ankyrin repeats of an adjacent subunit (which presumably is important for channel assembly) [42]. These features are similar to the T1 domain of Kv channels where this region plays an important role in subunit assembly [43]. On the other hand, the wider outer pore and the shorter selectivity filter of TRPV1 also point to similarities with bacterial Nav channels [42].

Then, a better resolution (3.4 $\AA$ ) 3D structure for TRPV1 was obtained, evidencing amino acid side chains and $\beta$-sheets located in the cytosolic domain of the protein [42] (Figure 2b). This ultra-structural analysis also described the tetrameric TRPV1 structure with a central ion conduction pore conformed by two transmembrane $\alpha$-helices (S5-S6) and a short pore helix (S5-P-S6), together with a voltage-sensor like domain consisting of a cluster of four transmembrane $\alpha$-helices (S1-S4) [42] (Figure 2b). The structural details of TRPV1 were primarily confirmed by this new model, suggesting that the TRPV1 channel shares many structural features with voltage-gated channels and potassium channels. However, 
unlike $\mathrm{Kv}$ channels, TRPV1 is not strongly voltage-dependent due to the lack of positively-charged residues in S4 [42].

Moreover, this approach also allowed for the resolution of the "TRP domain" within the Cterminus. It was revealed that this conserved 25 amino acid domain consists of an $\alpha$-helical structure parallel to the membrane, that encompasses the first two-thirds of the TRP domain and interacts with the S4-S5 linker (Figure 2b). Thus, the TRP helix seems to have a critical role in integrating allosteric modulation between the domains of the channel [42].

\subsection{Intracellular TRPV1 Localization}

After the discovery of TRPV1 as a protein expressed in the plasma membrane of small and medium-sized DRG neurons [22-24], its intracellular location was also reported [24,44-46] (Table 1). Initially, TRPV1 localization in organelles was determined in DRG neurons and TRPV1-expressing COS7 cells by using confocal and electron microscopy, demonstrating for the first time that TRPV1 was found in intracellular compartments (such as the ER) of these cells [44,46-48]. Further reports also revealed internal TRPV1 localization in the mitochondria and ER of TRPV1-expressing HEK293 cells, cardiomyocytes, glial cells, and muscle cells, among others [45,49-52] (Table 1). Intracellular localization in diverse types of TRPV1-expressing cells highlights its specificity and rules out effects of overexpression of the channel in transfected HEK293 cells [53] (Table 1).

Table 1. Intracellular localization of the TRPV1 channels in different cell types. DRG: dorsal root ganglion.

\begin{tabular}{ccc}
\hline Intracellular Localization & Cell Type & Reference \\
\hline \multirow{3}{*}{ Mitochondria } & Murine cardiomyocytes & {$[51]$} \\
\cline { 2 - 3 } & Microglial cells & {$[49]$} \\
\cline { 2 - 3 } & Heart-derived H9C2 cells & {$[51,54]$} \\
\cline { 2 - 3 } & Human parietal cells & {$[55]$} \\
\cline { 2 - 3 } & Human odontoblast-like cells & {$[56]$} \\
\cline { 2 - 3 } Endoplasmic Reticulum & Dirway smooth muscle cells & {$[57]$} \\
\cline { 2 - 3 } & TRPV1-expressing cells: & {$[50]$} \\
\hline Sarcoplasmic Reticulum & HEK293, COS7, Sf9, HeLa & {$[44-47,52,58]$} \\
\hline \multirow{2}{*}{ Golgi Complex } & Skeletal muscle cells & {$[59,60]$} \\
\hline & DRG neurons & {$[24]$} \\
\hline Lysosome & Microglia cells & {$[49]$} \\
\hline
\end{tabular}

TRPV1 expression has also been detected in rat skeletal muscle, where this channel is mainly located in the sarcoplasmic reticulum [60], and it has been suggested to contribute to the regulation of excitation and contraction through $\mathrm{Ca}^{2+}$ homeostasis [59]. Particularly, TRPV1 has been isolated from membrane fractions located at longitudinal sarcoplasmic reticula [59]. Besides, proximity ligation assays achieved in human airway smooth muscle (ASM) cells indicated that TRPV1 is expressed in a fashion where it is closely associated to sarco/endoplasmic reticulum $\mathrm{Ca}^{2+}$-ATPase (SERCA) pumps [50].

Furthermore, the co-localization of TRPV1 has been reported with the $58 \mathrm{~K}$ Golgin protein (a marker of the Golgi complex) in microglial cells, suggesting its localization in this internal cell compartment [49]. 
Also, TRPV1 protein has been visualized in the Golgi compartment of small-diameter DRG neurons and forming aggregates in the Golgi of some breast cancer cell lines [24,61] (Table 1). These findings could suggest the presence of an available pool of functional channels located in the Golgi or of channels being transported to the plasma membrane, an observation that needs more detailed analysis.

Remarkably, several reports support the intracellular availability of TRPV1 channels in the form of functional pools, enhancing the versatility of this channel as a cell surface signal transducer and a regulator of $\mathrm{Ca}^{2+}$ mobilization between the cytosol and some organelles [45-47]. Additionally, several reports show that the activation of TRPV1 channels located in the cell surface also play an essential role in regulating $\mathrm{Ca}^{2+}$ homeostasis of intracellular compartments, such as the mitochondria, as is described below.

\subsection{TRPV1 Channels: Their Mitochondrial Actions in Non-Neuronal Cells}

Mitochondrial TRPV1 localization has been mainly reported in non-neuronal cells; for example, it has been detected in cardiac mitochondrial fractions derived from mice [62]. Moreover, using confocal microscopy, it has been determined that TRPV1 displays co-localization with mitochondrial-resident proteins in primary neonatal cardiomyocytes [51]. Similarly, human parietal cells and human odontoblast-like cells exhibit positive mitochondrial immunostaining for TRPV1 [55,56], and recently, it has been reported that this channel is expressed in endothelial cells and found in the mitochondria [57] (Table 1).

Reports from different laboratories have shown that TRPV1 activation has beneficial consequences for mitochondrial function and regulates cell physiology. For example, an initial report demonstrated that microglia derived from WT mice display TRPV1 channels that are abundantly co-localized with specific markers of mitochondria, ER, Golgi complex and lysosomes. However, intriguingly, these cells lack TRPV1 at their cell surface [49]. Accordingly, whole-cell patch-clamp recordings showed that microglia lack capsaicin-evoked currents, although they display increased intramitochondrial $\mathrm{Ca}^{2+}$ produced by TRPV1 activation that lead to mitochondrial depolarization. These observations were obtained using time-lapse imaging of an intramitochondrial $\mathrm{Ca}^{2+}$-sensitive fluorescent dye (Rhod-5N) and with a confocal laser-scanning microscope to detect changes in the fluorescence emission of the cationic JC-1 dye, which changes its emission in response to variations in mitochondrial membrane potential. The changes observed suggested that capsaicin modifies mitochondrial $\mathrm{Ca}^{2+}$ and its membrane potential, presumably through TRPV1 channels localized to this compartment [49]. Interestingly, microglia derived from TRPV1-KO mice and treated with capsaicin displayed no changes in both parameters, indicating that the effects observed in the WT mice require the expression of TRPV1 channels in these cells. The cellular effects that arise from changes in $\mathrm{Ca}^{2+}$ levels in the mitochondria of these cells yield reactive oxygen species (mitROS) from this compartment which, in turn, act on the mitogen-activated protein kinase (MAPK) signaling pathway to induce microglial migration [49]. This exemplifies how the intracellular activity of TRPV1 influences cell processes such as cell migration.

Similarly, primary neonatal cardiomyocytes analyzed by confocal immunofluorescence and electron microscopy have revealed that these channels are located in the mitochondria, while they are scarce in the cell surface. At the same time, it has been reported that TRPV1 activation in these cells decreases the fluorescence intensity from mitochondria labeled with tetramethylrhodamine ethyl ester (TMRE; an indicator of active mitochondria) in cell imaging experiments, indicating changes in the mitochondrial membrane potential of these cells [51]. This effect was prevented by the co-treatment with capsaicin and capsazepine (a TRPV1 antagonist), showing that TRPV1 activation modifies mitochondrial function. Unexpectedly, this effect was also prevented by cyclosporine A, which is a calcineurin inhibitor. Calcineurin is a crucial mediator of TRPV1 desensitization [35], and Hurt and collaborators have reported that calcineurin directly interacts within the TRPV1 C-terminus, favoring channel dephosphorylation and providing negative feedback regulation through calmodulin [51]. Additionally, TRPV1 dephosphorylation through calcineurin's actions primes the channel to be reactivated by recovering its phosphorylated state through actions of $\mathrm{Ca}^{2+}$ 
calmodulin-dependent kinase II (CaMKII) [63]. Thus, the cyclosporine A effects on cardiomyocytes where mitochondrial membrane potential decreases, i.e., as produced by capsaicin, could be caused through the disruption of the dephosphorylation/phosphorylation cycle of the TRPV1 channel.

Furthermore, using a myocardial infarction rodent model, Hurt and collaborators demonstrated that capsaicin decreases the infarct area, an effect that was also blocked by capsazepine and by cyclosporine A, suggesting that TRPV1 activation produces protective effects against reperfusion injury in this myocardial infarction model [51].

Additionally, Lang and collaborators have also identified the TRPV1 in cardiac mitochondrial protein fractions from WT mice [62] and have reported that mice fed with a chronic high salt diet display mitochondrial dysfunction, which is ameliorated by the concomitant administration of this diet and capsaicin, and not when capsaicin is co-administered to the TRPV1-KO mice, which confirmed that TRPV1 activation diminishes mitochondrial dysfunction produced by this type of diet. Remarkably, in mice treated with capsaicin, cardiac mitochondrial enzyme function and expression were restored (i.e., Sirtuin 3), suggesting that TRPV1 improves cardiac dysfunction [62].

Furthermore, using a cardiovascular disease mice model in $A p o e^{-/-}$mice fed with a high fat diet, mitochondrial dysfunction and cardiac injury were also observed, but these alterations were partially prevented by co-feeding them with capsaicin. This protective effect is not observed in the double knockout $A p o e^{-/} / \operatorname{Trpv}^{-/-}$mice, suggesting that TRPV1 channels are required for the improvement of heart function by capsaicin [64]. These results reinforced the notion that TRPV1 offers heart protective roles in different animal models displaying cardiac mitochondrial dysfunction. Similar effects have also been detected in the H9C2 cell line (rat heart tissue-derived cardiac myoblast cell line), because when these cells are subjected to ischemia-reoxygenation processes and treated with low capsaicin concentrations, they display an improvement in cell damage [51].

In contrast, other authors have reported that TRPV1 activation produces harmful effects for mitochondria and cardiac tissue. For instance, it was reported that $\mathrm{H} 9 \mathrm{C} 2$ cells exposed to hypoxia-reoxygenation (H-R) conditions show reduced cell viability, which is potentiated by a high dose of capsaicin. This effect is achieved by increasing intracellular $\mathrm{Ca}^{2+}$, reducing the mitochondrial membrane potential and elevating mitochondrial superoxide production, leading to apoptosis of these cells [54]. Importantly, all of these effects are potentiated by capsaicin and attenuated by capsazepine. These evidences suggest that there are dose-dependent effects for capsaicin and that this compound promotes dual effects by either preventing or intensifying mitochondrial dysfunction in $\mathrm{H} 9 \mathrm{C} 2$ cells depending on the concentration of vanilloid used in the experiments. Curiously, these cells display low TRPV1 expression, with channels mainly located at the ER where their activation increases cytosolic and mitochondrial $\mathrm{Ca}^{2+}$ levels, suggesting that TRPV1 channels localized at the ER could work as $\mathrm{Ca}^{2+}$ exchangers between the ER and the mitochondria [65], a role that needs to be studied in further detail. In addition, H9C2 cells exposed to H-R conditions display increases in TRPV1 phosphorylation, indicating channel sensitization. This finding is in agreement with a previous report performed using DRG neurons exposed to hypoxia conditions [66], where channel phosphorylation of serine residues increased due to the induction of hypoxia-inducible factor- 1 alpha (HIF-1 $\alpha)$. The latter regulates protein kinase $\mathrm{C}$ epsilon (PKCE) translocation to the plasma membrane, then this kinase phosphorylates serine 800 located at the TRPV1 C-terminus [66]. This evidence reinforces that the TRPV1 channel is sensitized by hypoxic conditions in different cell contexts, suggesting that capsaicin produces a synergic effect on a channel previously sensitized by an $\mathrm{H}-\mathrm{R}$ condition in $\mathrm{H} 9 \mathrm{C} 2$ cells, resulting in cell death.

In support of the evidence provided here for the effects of TRPV1 activation on mitochondrial dysfunction, some ischemia-reperfusion experiments performed in ex vivo hearts from WT and TRPV1-KO mice have revealed that the TRPV1-lacking hearts show improvement in cardiac function, suggesting that TRPV1 channels play an essential role in reperfusion injury [54]. In addition, the recent characterization of TRPV1 expression in endothelial cells and its intracellular localization has allowed us for the reinforcement of its role in endothelial dysfunction. Human endothelial cells treated with 
12-(S)-HETE (an arachidonic acid metabolite and a partial agonist of TRPV1 [30]) display increased mitochondrial $\mathrm{Ca}^{2+}$, reduced oxygen consumption rates and decreased mitochondrial membrane potentials, all of which are indicators of mitochondrial dysfunction. These indicators are also present when human endothelial cells are treated with capsaicin [57]. Interestingly, streptozotocin-induced diabetic mice exhibit increased 12-(S)-HETE levels and show impaired vascular regeneration, while in TRPV1-KO mice treated with streptozotocin, there is protection against this impairment even when their 12-(S)-HETE levels are also increased. These results suggest that TRPV1 activation by 12-(S)-HETE in diabetic mice deteriorates mitochondrial and endothelial function, favoring vascular disease [57].

Similarly, it has been reported that 13-(S)-HODE (an endogenous TRPV1 agonist derived from linoleic acid [32]) causes mitochondrial dysfunction in airway epithelial cells through TRPV1 activation, which induces epithelial injury [67]. It was demonstrated in human bronchial epithelial cells exposed to 13-(S)-HODE that these cells exhibited mitochondrial $\mathrm{Ca}^{2+}$ overload and enhanced cytoplasmatic cytochrome $\mathrm{C}$. Mitochondrial alterations were partially prevented by capsazepine or by using a siRNA to downregulate TRPV1 expression [67]. Interestingly, patients with atopic asthma display high levels of 13-(S)-HODE in sera, bronchoalveolar lavage, and sputum supernatants [67]. Thus, it is feasible to hypothesize that this fatty acid activates TRPV1 channels expressed in the airway epithelia, exacerbating mitochondrial dysfunction. Hence, TRPV1 and enzymes that produce this fatty acid (lipoxygenase) could be targets for the treatment of airway pathologies such as atopic asthma.

\subsection{TRPV1 Channels and Mitochondrial Dysfunction in Neuronal Cells}

Until now, there has been scarce evidence showing mitochondrial localization for TRPV1 in DRG neurons. In contrast, there are data supporting the TRPV1 roles in mitochondrial $\mathrm{Ca}^{2+}$ homeostasis in these cells, affecting cell viability, as has been determined in primary DRG neuronal cultures treated with resiniferatoxin and capsaicin $[46,68,69]$. These neurons display severe mitochondrial fragmentation after treatment with the aforementioned compounds, indicating that $\mathrm{Ca}^{2+}$ influx through TRPV1 channels produced organelle disruption [46]. Other reports have confirmed that DRG neurons treated with high concentrations of capsaicin or prolonged exposure to vanilloids display disturbances in their mitochondrial transmembrane potential and apoptotic cell death occurs [68] (Figure 3a).

We have to remember that the primordial functions of mitochondria are the production of energy, the scavenging of reactive oxygen species (ROS, which are co-produced with ATP), and buffering cytoplasmatic $\mathrm{Ca}^{2+}$ overload. The latter results are relevant to neuronal $\mathrm{Ca}^{2+}$ homeostasis, and require coordinated actions between the mitochondrial $\mathrm{Ca}^{2+}$ uniporter (MCU) that takes up cytoplasmic $\mathrm{Ca}^{2+}$, the $\mathrm{Na}^{+} / \mathrm{Ca}^{2+} / \mathrm{Li}^{2+}$ exchanger (NCLX) that mediates sodium-dependent $\mathrm{Ca}^{2+}$ efflux, and the permeability transition pore (PTP). The overload of mitochondrial $\mathrm{Ca}^{2+}$ uptake causes the opening of the PTP, releasing cytochrome $C$ and inducing apoptosis [70] (Figure 3a). Interestingly, several reports have shown that mitochondria are also essential players in the pain response, since they can regulate the duration of the harmful signal transmission [71]. These effects have also been linked to the activation of TRPV1.

The toxic effects produced by mitochondrial $\mathrm{Ca}^{2+}$ overload have been studied in DRG neurons dissected from a rat spinal cord injury model. These neurons display decreased mitochondrial membrane potentials, and concomitantly increased ROS production and activation of caspases 3 and 9, compromising neuron viability and leading to apoptosis [72]. These effects are partially dependent upon TRPV1 activation [72]. 


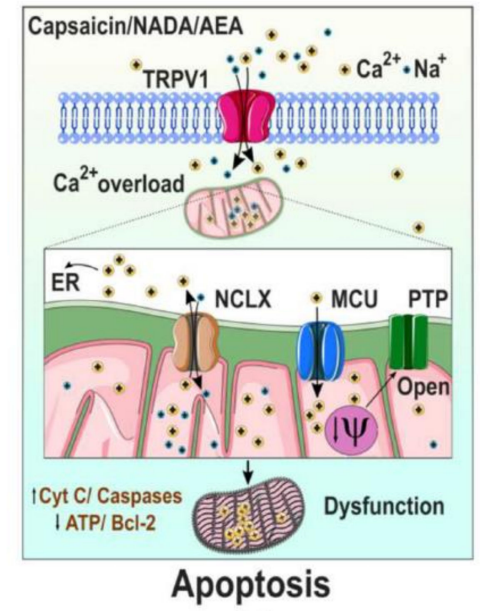

(a)

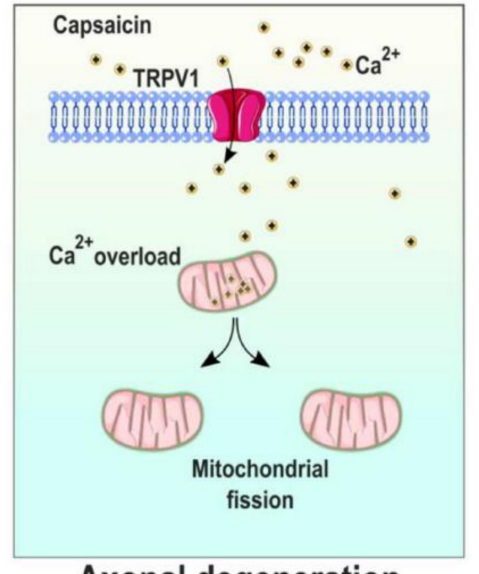

Axonal degeneration

(b)

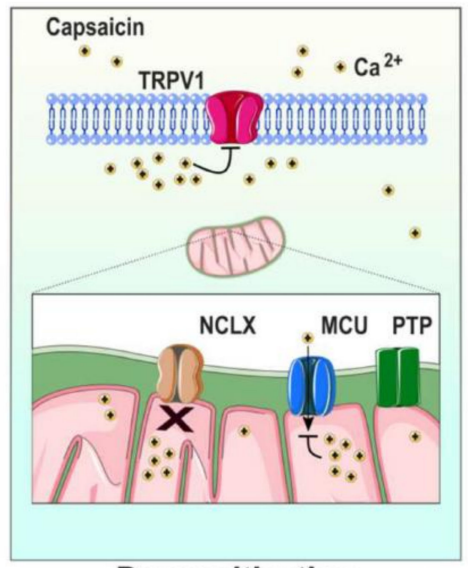

Desensitization

(c)

Figure 3. Scheme representing plasmatic TRPV1 actions on mitochondria. (a) Prolonged activation of TRPV1 leads to $\mathrm{Ca}^{2+}$ overload into the mitochondria. This effect triggers mitochondrial depolarization, releases cytochrome $\mathrm{C}$ through the permeability transition pore (PTP) and induces apoptosis. (b) Activation of TRPV1 induces the mitochondrial fission and produces axonal degeneration. (c) Downregulation of the $\mathrm{Na}^{+} / \mathrm{Ca}^{2+} / \mathrm{Li}^{2+}$ exchanger (NCLX) expression avoids the release of $\mathrm{Ca}^{2+}$ from the mitochondria, which inhibits mitochondrial $\mathrm{Ca}^{2+}$ uptake through the mitochondrial $\mathrm{Ca}^{2+}$ uniporter (MCU), leading to accumulation of cytosolic $\mathrm{Ca}^{2+}$ and inducing TRPV1 desensitization. ER: endoplasmic reticulum. AEA: $\mathrm{N}$-arachidonoylethanolamine or Anandamide. NADA: N-Arachidonoyl-Dopamine.

Mitochondrial $\mathrm{Ca}^{2+}$ overload and cell death in DRG neurons treated with vanilloids seem to be specific for TRPV1, since activation of TRPA1 does not produce this overload even if cytoplasmatic $\mathrm{Ca}^{2+}$ increases [69], reinforcing the specificity of TRPV1's effects on mobilization of mitochondrial $\mathrm{Ca}^{2+}$. These results were confirmed through experiments performed in TRPV1-expressing HEK293 cells, where capsaicin treatment modified mitochondrial potential and caused cell death. Notably, TRPV1 activation by extracellular acid $\mathrm{pH}$ in these cells does not affect mitochondrial function nor cell viability, suggesting that cell lethality by TRPV1 activation depends on the type of agonist present [69]. It could also indicate that protons cannot activate intracellularly located channels, so $\mathrm{Ca}^{2+}$ mobilization is not internally magnified, preventing cell death. Moreover, experiments performed with TRPV1-transfected HeLa cells have revealed that treatments with low capsaicin concentrations produced changes in the plasma membrane's integrity, leading to necrotic cell death. In contrast, cells treated with high capsaicin concentrations show mitochondrial dysfunction and apoptotic cell death [73] (Figure 3a). Together, this evidence suggests that different doses of capsaicin trigger distinct molecular pathways to induce the same result: cell death.

The toxic effects of vanilloids have also been evidenced in neurons from the central nervous system [74]. For example, the identification of TRPV1 expression in dopaminergic neurons allowed for the exploration of the effects of TRPV1 agonists in these cells, demonstrating that high doses of capsaicin induce mitochondrial dysfunction and cell death. Similarly, anandamide, an endogenous agonist of the cannabinoid receptor 1 (CB1) and of TRPV1, causes these effects by activating both receptors, suggesting that an excessive local production of anandamide or any endogenous agonist of these receptors could induce neuronal damage through these proteins [74]. Cell death-inducing TRPV1 effects have also been observed in the neuronal TRPV1-transfected cell line, SH-SY5Y. The treatment of these cells with capsaicin or with the endogenous TRPV1 agonist, N-arachidonoyl-dopamine (NADA), or with anandamide (AEA), produced apoptotic cell death [75] (Figure 3a).

Additionally, it has been demonstrated that capsaicin produces axonal degeneration in sensory neurons through a mechanism that affects mitochondrial dynamics. $\mathrm{Ca}^{2+}$ overload produced by 
TRPV1's activation induces axonal swelling and mitochondrial fission, blocking axonal regeneration [76] (Figure 3b). Remarkably, this could have two effects, depending on the type of neurons involved. For instance, in sensory neurons, axonal degeneration could produce neuronal dysfunction resulting in the block of the transduction and transmission of noxious stimuli, yielding an analgesic effect. In contrast, effects of capsaicin on neurons from the central nervous system could produce cell death, leading to neurodegenerative diseases [76].

The evidence described above suggests that TRPV1 activation causes mitochondrial $\mathrm{Ca}^{2+}$ unbalance, disrupting the mitochondrial membrane potential, inducing increased ROS production and cytochrome $\mathrm{C}$ release and leading to apoptosis (Figure 3a). TRPV1 activation and $\mathrm{Ca}^{2+}$ overload are not always harmful to mitochondria; some reports have also shown that a rise in $\mathrm{Ca}^{2+}$ can be buffered by this organelle and serve as a regulator of the painful response. For instance, DRG neurons exposed to capsaicin exhibit fast $\mathrm{Ca}^{2+}$ intracellular rises, which are buffered by their mitochondria. $\mathrm{Next}, \mathrm{Ca}^{2+}$ is slowly released from this organelle, ensuring the maintenance of elevated cytosolic $\mathrm{Ca}^{2+}$ and, in parallel, TRPV1 desensitization could also occur [77].

Similarly, it has been demonstrated that knockdown of NCLX in DRG neurons decreases capsaicin-evoked action potentials. These neurons maintain the increase of cytosolic $\mathrm{Ca}^{2+}$ produced through TRPV1 activation, facilitating channel desensitization [78] (Figure 3c). These data reinforce the idea that intracellular $\mathrm{Ca}^{2+}$ overloads produced by TRPV1 activation are buffered by mitochondrial transporters, resulting in the modulation of TRPV1 function and leading to the regulation of the way noxious signals are transduced through this channel [78].

Furthermore, experiments performed with DRG and spinal cord neuron co-cultures evidenced that a sustained mitochondrial $\mathrm{Ca}^{2+}$ mobilization facilitates neurotransmitter release from presynaptic neurons, inducing the firing of action potentials from postsynaptic neurons. Remarkably, the duration of postsynaptic activity depends on presynaptic stimuli strength, where an intense stimulation (such as a high capsaicin concentration) induces long-lasting postsynaptic activity. This effect is independent of extracellular $\mathrm{Ca}^{2+}$, but it depends on the proper function of the presynaptic mitochondria [79].

Sensory neurons display numerous mitochondria located in the synaptic buttons, providing energy and clearing intracellular $\mathrm{Ca}^{2+}$ from presynaptic neurons [80]. Thus, mitochondria provide a long-lasting effect of pain signal transmission by dodging the $\mathrm{Ca}^{2+}$-dependent desensitization of some ion channels, such as TRPV1, and this exemplifies the close relationship between mitochondrial $\mathrm{Ca}^{2+}$ mobilization and the maintenance of noxious signal transmission so that a sustained pain response can be produced.

\section{Conclusions}

Mitochondria are organelles that not only function as producers of cellular ATP, but also perform essential roles in prompting apoptotic cell death. Many apoptotic stimuli can lead to the liberation of specific mitochondrial pro-apoptotic factors into the cytosol and, although the molecular mechanism underlying this is still under debate, mitochondrial $\mathrm{Ca}^{2+}$ overload is definitely one of the signals involved in swelling of mitochondria, rupture of their outer membranes, and release of mitochondrial apoptotic factors into the cytosol.

As a result of this mitochondrial dysfunction, disorders such as those of an inflammatory nociceptive nature where there is sensory nerve hyperexcitability are also produced. Signals that produce mitochondrial dysfunction result in the production of ROS, mitochondrial depolarization and $\mathrm{Ca}^{2+}$ release, regulating cellular signaling. A link between this and nociception has been highlighted in the last few years and TRPV1 has emerged as an important effector of this through the regulation of mitochondrial function.

Several reports have evidenced how TRPV1 activation modifies mitochondrial function in non-neuronal and neuronal cells. There are still several questions that must be answered in relation to mitochondrial TRPV1 localization, although most of the studies described here show that TRPV1 
activation has a pivotal influence on mitochondrial $\mathrm{Ca}^{2+}$ homeostasis, the mitochondrial channel localization is still a fertile field to explore.

This review summarizes the works describing TRPV1 protein detection in the mitochondrial fraction of cardiac tissue and also the reports showing channel expression in primary neonatal cardiomyocytes, microglia, and the H9C2 cell line $[49,51,54]$. The localization of this channel in the mitochondria has been based on the co-localization of the channel with specific mitochondrial markers. However, these studies have not discerned if the TRPV1 signal observed arises from the channel located in the mitochondria-associated ER membranes (MAM), which are microdomains of the ER with close proximity to the mitochondria. It is possible to speculate the latter, since it has recently been characterized that TRPV1 directly interacts with the Sigma-1 receptor [81], a protein highly enriched in the MAM [82], and implicated in the regulation of interorganellar $\mathrm{Ca}^{2+}$ between ER and mitochondria [82].

We also speculate that TRPV1 could associate to the mitochondrial membrane; nonetheless, the only approach that has suggested this is one where electron microscopy was used, and where it was shown that immunogold labeling of TRPV1 displayed an irregular distribution in the mitochondria from neonatal cardiomyocytes. Hence, mitochondrial channel distribution in these cells was not limited to the mitochondrial membrane as could be hypothesized.

These works reveal that it is still necessary to conduct in-depth tests to clarify if TRPV1 channels are really located in the mitochondrial membrane and to elucidate the topological orientation of the channel in this organelle. Moreover, it will be interesting to study isolated mitochondria from non-neuronal and neuronal cells to determine if TRPV1 is directly located in the mitochondria and moreover if capsaicin treatment of these isolated mitochondria could directly modify the membrane potential of this organelle (i.e., electrophysiological recordings).

From the advances we have observed in the last few years, the field of study of the role of proteins such as TRPV1 in mitochondrial function is one that promises to yield rich information on how apoptosis and/or pain are regulated by ion channels at the subcellular level.

Author Contributions: Conceptualization, S.L.M.-L.; writing-original draft preparation, R.J.-C., K.A.M.-R., R.G.-R. and S.L.M.-L.; writing-review and editing, T.R. and S.L.M.-L.; supervision, S.L.M.-L. All authors have read and agreed to the published version of the manuscript.

Funding: This research was funded by the Dirección General de Asuntos del Personal Académico (DGAPA)-Programa de Apoyo a Proyectos de Investigación e Innovación Tecnológica (PAPIIT) IN206819 and Estímulos a Investigaciones Médicas Miguel Alemán Valdés to S.L.M.-L. The APC was funded by PAPIIT IN206819. This work also was supported by the Consejo Nacional de Ciencia y Tecnología (CONACyT) A1-S-8760, CONACyT-Fronteras de la Ciencia 77, Secretaría de Educación, Ciencia, Tecnología e Innovación del Gobierno de la Ciudad de México SECTEI/208/2019 and PAPIIT IN200720 to T.R.

Acknowledgments: This work comprises part of the Ph.D. studies of R.J.-C. in the Posgrado en Ciencias Biológicas de la Universidad Nacional Autónoma de México and the Ph.D. thesis work of K.A.M.-R., a student in the Programa de Doctorado en Ciencias Biomédicas, Universidad Nacional Autónoma de México. We thank Alejandra Llorente for the elaboration of tables and her administrative support.

Conflicts of Interest: The authors declare no conflict of interest.

\section{Abbreviations}

$\begin{array}{ll}\text { Apoe }^{-/} \text {mice } & \text { Atherosclerosis-prone apolipoprotein E-deficient mice } \\ \text { ARD } & \text { Ankyrin Repeats Domain } \\ \text { ASM } & \text { Airway Smooth Muscle } \\ \text { ATP } & \text { Adenosine Triphosphate } \\ \text { CaM } & \text { Calmodulin } \\ \text { CB1 } & \text { Cannabinoid Receptor 1 } \\ \text { cDNAs } & \text { Complementary DNA } \\ \text { COS7 cell } & \text { Fibroblast-like cell line derived from monkey kidney tissue } \\ \text { cryo-EM } & \text { Single-Particle Electron Cryo-Microscopy } \\ \text { C-terminus } & \text { Carboxyl-terminus }\end{array}$




\begin{tabular}{|c|c|}
\hline DRG & Dorsal Root Ganglion \\
\hline ER & Endoplasmic Reticulum \\
\hline $\mathrm{H} / \mathrm{R}$ & Hypoxia/Reoxygenation \\
\hline H9C2 cell line & Rat heart tissue-derived cardiac myoblast cell line \\
\hline HEK293 cells & Human embryonic kidney 293 cells line \\
\hline HeLa cells & Human Cervix Epithelial Carcinoma cell line \\
\hline Kv channels & Voltage-gated $\mathrm{K}^{+}$channels \\
\hline LPA & Lysophosphatidic Acid \\
\hline MAPK pathway & Mitogen-Activated Protein Kinase pathway \\
\hline MCU & Mitochondrial $\mathrm{Ca}^{2+}$ Uniporter \\
\hline mitROS & Mitochondrial reactive oxygen species \\
\hline NADA & $\mathrm{N}$-arachidonoyl-dopamine \\
\hline NCLX & $\mathrm{Na}+/ \mathrm{Ca}^{2+} / \mathrm{Li}^{2+}$ exchanger \\
\hline N-terminus & Amino-terminus \\
\hline RNA & Ribonucleic Acid \\
\hline ROS & Reactive Oxygen Species \\
\hline SERCA & Sarco/Endoplasmic Reticulum $\mathrm{Ca}^{2+}$-ATPase \\
\hline SH-SY5Y cell & Human neuroblastoma cell line \\
\hline S1-S6 & Transmembrane segments $1-6$ \\
\hline TG & Trigeminal Ganglion \\
\hline TRP & Transient Receptor Potentials \\
\hline TRPA & Transient Receptor Potentials Ankyrin \\
\hline TRPA1 & Transient Receptor Potential Ankyrin 1 \\
\hline TRPC & Transient Receptor Potentials Canonical \\
\hline TRPC1 & Transient Receptor Potential Channel-related 1 \\
\hline TRPC3 & Transient Receptor Potential Canonical type 3 \\
\hline trpl & Transient Receptor Potential-Like \\
\hline $\operatorname{trp}$ & Transient Receptor Potential Mutant \\
\hline TRPM & Transient Receptor Potentials Melastatin \\
\hline TRPM8 & Transient Receptor Potential Melastatin Member 8 \\
\hline TRPML & Transient Receptor Potentials Mucolipin \\
\hline TRPML1 & Transient Receptor Potential Mucolipin 1 \\
\hline TRPN & Transient Receptor Potentials No Mechanoreceptor \\
\hline TRPP & Transient Receptor Potentials Polycystin \\
\hline TRPP1 & Transient Receptor Potential Polycystin 1 \\
\hline TRPV & Transient Receptor Potentials Vanilloid \\
\hline TRPV1 & The Transient Receptor Vanilloid 1 \\
\hline $\operatorname{Trpv} 1^{--}$ & Transient Receptor Potential Vanilloid 1 Knockout \\
\hline TRPV1-KO & Transient Receptor Potential Vanilloid 1 Knockout \\
\hline TRPY & Transient Receptor Potentials Yeast \\
\hline WT & Wild-Type \\
\hline $3 \mathrm{D}$ & Three-dimensional \\
\hline 12-(S)-HETE & 12S-hydroxy-5Z,8Z,10E,14Z-eicosatetraenoic acid \\
\hline 13-(S)-HODE & 13(S)-Hydroxy-9Z,11E-octadecadienoic acid \\
\hline
\end{tabular}

\section{References}

1. Cosens, D.J.; Manning, A. Abnormal electroretinogram from a Drosophila mutant. Nature 1969, 224, $285-287$. [CrossRef] [PubMed]

2. Cosens, D. Blindness in a Drosophila mutant. J. Insect Physiol. 1971, 17, 285-302. [CrossRef]

3. Pak, W.L. Why Drosophila to study phototransduction? J. Neurogenet 2010, 24, 55-66. [CrossRef] [PubMed]

4. Minke, B.; Wu, C.; Pak, W.L. Induction of photoreceptor voltage noise in the dark in Drosophila mutant. Nature 1975, 258, 84-87. [CrossRef]

5. Barash, S.; Suss, E.; Stavenga, D.G.; Rubinstein, C.T.; Selinger, Z.; Minke, B. Light reduces the excitation efficiency in the nss mutant of the sheep blowfly Lucilia. J. Gen. Physiol. 1988, 92, 307-330. [CrossRef] 
6. Minke, B. Light-induced reduction in excitation efficiency in the trp mutant of Drosophila. J. Gen. Physiol. 1982, 79, 361-385. [CrossRef]

7. Montell, C.; Jones, K.; Hafen, E.; Rubin, G. Rescue of the Drosophila phototransduction mutation trp by germline transformation. Science 1985, 230, 1040-1043. [CrossRef] [PubMed]

8. Wong, F.; Hokanson, K.M.; Chang, L.T. Molecular basis of an inherited retinal defect in Drosophila. Investig. Ophthalmol. Vis. Sci. 1985, 26, 243-246.

9. Montell, C.; Rubin, G.M. Molecular characterization of the Drosophila trp locus: A putative integral membrane protein required for phototransduction. Neuron 1989, 2, 1313-1323. [CrossRef]

10. Wong, F.; Schaefer, E.L.; Roop, B.C.; LaMendola, J.N.; Johnson-Seaton, D.; Shao, D. Proper function of the Drosophila trp gene product during pupal development is important for normal visual transduction in the adult. Neuron 1989, 3, 81-94. [CrossRef]

11. Minke, B. Drosophila mutant with a transducer defect. Eur. Biophys. J. 1977, 3, 59-64. [CrossRef] [PubMed]

12. Suss-Toby, E.; Selinger, Z.; Minke, B. Lanthanum reduces the excitation efficiency in fly photoreceptors. J. Gen. Physiol. 1991, 98, 849-868. [CrossRef] [PubMed]

13. Minke, B.; Selinger, Z. The inositol-lipid pathway is necessary for light excitation in fly photoreceptors. Soc. Gen. Physiol. Ser. 1992, 47, 201-217.

14. Hardie, R.C.; Minke, B. The trp gene is essential for a light-activated $\mathrm{Ca}^{2+}$ channel in Drosophila photoreceptors. Neuron 1992, 8, 643-651. [CrossRef]

15. Phillips, A.M.; Bull, A.; Kelly, L.E. Identification of a Drosophila gene encoding a calmodulin-binding protein with homology to the trp phototransduction gene. Neuron 1992, 8, 631-642. [CrossRef]

16. Wes, P.D.; Chevesich, J.; Jeromin, A.; Rosenberg, C.; Stetten, G.; Montell, C. TRPC1, a human homolog of a Drosophila store-operated channel. Proc. Natl. Acad. Sci. USA 1995, 92, 9652-9656. [CrossRef]

17. Venkatachalam, K.; Montell, C. TRP channels. Annu. Rev. Biochem. 2007, 76, 387-417. [CrossRef]

18. Palmer, C.P.; Zhou, X.L.; Lin, J.; Loukin, S.H.; Kung, C.; Saimi, Y. A TRP homolog in Saccharomyces cerevisiae forms an intracellular $\mathrm{Ca}(2+)$-permeable channel in the yeast vacuolar membrane. Proc. Natl. Acad. Sci. USA 2001, 98, 7801-7805. [CrossRef]

19. Dong, X.P.; Wang, X.; Xu, H. TRP channels of intracellular membranes. J. Neurochem. 2010, 113, 313-328. [CrossRef]

20. Zhao, R.; Tsang, S.Y. Versatile Roles of Intracellularly Located TRPV1 Channel. J. Cell. Physiol. 2017, 232, 1957-1965. [CrossRef]

21. Caterina, M.J.; Leffler, A.; Malmberg, A.B.; Martin, W.J.; Trafton, J.; Petersen-Zeitz, K.R.; Koltzenburg, M.; Basbaum, A.I.; Julius, D. Impaired nociception and pain sensation in mice lacking the capsaicin receptor. Science 2000, 288, 306-313. [CrossRef]

22. Caterina, M.J.; Schumacher, M.A.; Tominaga, M.; Rosen, T.A.; Levine, J.D.; Julius, D. The capsaicin receptor: A heat-activated ion channel in the pain pathway. Nature 1997, 389, 816-824. [CrossRef]

23. Tominaga, M.; Caterina, M.J.; Malmberg, A.B.; Rosen, T.A.; Gilbert, H.; Skinner, K.; Raumann, B.E.; Basbaum, A.I.; Julius, D. The cloned capsaicin receptor integrates multiple pain-producing stimuli. Neuron 1998, 21, 531-543. [CrossRef]

24. Guo, A.; Vulchanova, L.; Wang, J.; Li, X.; Elde, R. Immunocytochemical localization of the vanilloid receptor 1 (VR1): Relationship to neuropeptides, the P2×3 purinoceptor and IB4 binding sites. Eur. J. Neurosci. 1999, 11, 946-958. [CrossRef]

25. Menigoz, A.; Boudes, M. The expression pattern of TRPV1 in brain. J. Neurosci. 2011, 31, 13025-13027. [CrossRef]

26. Peier, A.M.; Reeve, A.J.; Andersson, D.A.; Moqrich, A.; Earley, T.J.; Hergarden, A.C.; Story, G.M.; Colley, S.; Hogenesch, J.B.; McIntyre, P.; et al. A heat-sensitive TRP channel expressed in keratinocytes. Science 2002, 296, 2046-2049. [CrossRef]

27. Sand, C.A.; Grant, A.D.; Nandi, M. Vascular Expression of Transient Receptor Potential Vanilloid 1 (TRPV1). J. Histochem. Cytochem. 2015, 63, 449-453. [CrossRef]

28. Salazar, H.; Llorente, I.; Jara-Oseguera, A.; Garcia-Villegas, R.; Munari, M.; Gordon, S.E.; Islas, L.D.; Rosenbaum, T. A single N-terminal cysteine in TRPV1 determines activation by pungent compounds from onion and garlic. Nat. Neurosci. 2008, 11, 255-261. [CrossRef]

29. Dhaka, A.; Uzzell, V.; Dubin, A.E.; Mathur, J.; Petrus, M.; Bandell, M.; Patapoutian, A. TRPV1 is activated by both acidic and basic pH. J. Neurosci. 2009, 29, 153-158. [CrossRef] 
30. Hwang, S.W.; Cho, H.; Kwak, J.; Lee, S.Y.; Kang, C.J.; Jung, J.; Cho, S.; Min, K.H.; Suh, Y.G.; Kim, D.; et al. Direct activation of capsaicin receptors by products of lipoxygenases: Endogenous capsaicin-like substances. Proc. Natl. Acad. Sci. USA 2000, 97, 6155-6160. [CrossRef]

31. Nieto-Posadas, A.; Picazo-Juarez, G.; Llorente, I.; Jara-Oseguera, A.; Morales-Lazaro, S.; Escalante-Alcalde, D.; Islas, L.D.; Rosenbaum, T. Lysophosphatidic acid directly activates TRPV1 through a C-terminal binding site. Nat. Chem. Biol. 2011, 8, 78-85. [CrossRef] [PubMed]

32. Patwardhan, A.M.; Scotland, P.E.; Akopian, A.N.; Hargreaves, K.M. Activation of TRPV1 in the spinal cord by oxidized linoleic acid metabolites contributes to inflammatory hyperalgesia. Proc. Natl. Acad. Sci. USA 2009, 106, 18820-18824. [CrossRef]

33. Zygmunt, P.M.; Petersson, J.; Andersson, D.A.; Chuang, H.; Sorgard, M.; Di Marzo, V.; Julius, D.; Hogestatt, E.D. Vanilloid receptors on sensory nerves mediate the vasodilator action of anandamide. Nature 1999, 400, 452-457. [CrossRef]

34. Bhave, G.; Hu, H.J.; Glauner, K.S.; Zhu, W.; Wang, H.; Brasier, D.J.; Oxford, G.S.; Gereau, R.W.T. Protein kinase $\mathrm{C}$ phosphorylation sensitizes but does not activate the capsaicin receptor transient receptor potential vanilloid 1 (TRPV1). Proc. Natl. Acad. Sci. USA 2003, 100, 12480-12485. [CrossRef]

35. Mohapatra, D.P.; Nau, C. Regulation of $\mathrm{Ca}^{2+}$-dependent desensitization in the vanilloid receptor TRPV1 by calcineurin and cAMP-dependent protein kinase. J. Biol. Chem. 2005, 280, 13424-13432. [CrossRef]

36. Sanz-Salvador, L.; Andres-Borderia, A.; Ferrer-Montiel, A.; Planells-Cases, R. Agonist- and Ca ${ }^{2+}$-dependent desensitization of TRPV1 channel targets the receptor to lysosomes for degradation. J. Biol. Chem. 2012, 287, 19462-19471. [CrossRef]

37. Fischer, M.J.; Btesh, J.; McNaughton, P.A. Disrupting sensitization of transient receptor potential vanilloid subtype 1 inhibits inflammatory hyperalgesia. J. Neurosci. 2013, 33, 7407-7414. [CrossRef] [PubMed]

38. Lishko, P.V.; Procko, E.; Jin, X.; Phelps, C.B.; Gaudet, R. The ankyrin repeats of TRPV1 bind multiple ligands and modulate channel sensitivity. Neuron 2007, 54, 905-918. [CrossRef]

39. Rosenbaum, T.; Gordon-Shaag, A.; Munari, M.; Gordon, S.E. Ca ${ }^{2+} /$ calmodulin modulates TRPV1 activation by capsaicin. J. Gen. Physiol. 2004, 123, 53-62. [CrossRef] [PubMed]

40. Numazaki, M.; Tominaga, T.; Takeuchi, K.; Murayama, N.; Toyooka, H.; Tominaga, M. Structural determinant of TRPV1 desensitization interacts with calmodulin. Proc. Natl. Acad. Sci. USA 2003, 100, 8002-8006. [CrossRef] [PubMed]

41. Moiseenkova-Bell, V.Y.; Stanciu, L.A.; Serysheva, I.I.; Tobe, B.J.; Wensel, T.G. Structure of TRPV1 channel revealed by electron cryomicroscopy. Proc. Natl. Acad. Sci. USA 2008, 105, 7451-7455. [CrossRef]

42. Liao, M.; Cao, E.; Julius, D.; Cheng, Y. Structure of the TRPV1 ion channel determined by electron cryo-microscopy. Nature 2013, 504, 107-112. [CrossRef]

43. Strang, C.; Cushman, S.J.; DeRubeis, D.; Peterson, D.; Pfaffinger, P.J. A central role for the T1 domain in voltage-gated potassium channel formation and function. J. Biol. Chem. 2001, 276, 28493-28502. [CrossRef] [PubMed]

44. Eun, S.Y.; Jung, S.J.; Park, Y.K.; Kwak, J.; Kim, S.J.; Kim, J. Effects of capsaicin on Ca(2+) release from the intracellular $\mathrm{Ca}(2+)$ stores in the dorsal root ganglion cells of adult rats. Biochem. Biophys. Res. Commun. 2001, 285, 1114-1120. [CrossRef]

45. Liu, M.; Liu, M.C.; Magoulas, C.; Priestley, J.V.; Willmott, N.J. Versatile regulation of cytosolic Ca2+ by vanilloid receptor I in rat dorsal root ganglion neurons. J. Biol. Chem. 2003, 278, 5462-5472. [CrossRef]

46. Olah, Z.; Szabo, T.; Karai, L.; Hough, C.; Fields, R.D.; Caudle, R.M.; Blumberg, P.M.; Iadarola, M.J. Ligand-induced dynamic membrane changes and cell deletion conferred by vanilloid receptor 1. J. Biol. Chem. 2001, 276, 11021-11030. [CrossRef]

47. Gallego-Sandín, S.; Rodríguez-García, A.; Alonso, M.T.; García-Sancho, J. The endoplasmic reticulum of dorsal root ganglion neurons contains functional TRPV1 channels. J. Biol. Chem. 2009, 284, 32591-32601. [CrossRef] [PubMed]

48. Karai, L.J.; Russell, J.T.; Iadarola, M.J.; Olah, Z. Vanilloid receptor 1 regulates multiple calcium compartments and contributes to $\mathrm{Ca}^{2+}$-induced $\mathrm{Ca}^{2+}$ release in sensory neurons. J. Biol. Chem. 2004, 279, 16377-16387. [CrossRef]

49. Miyake, T.; Shirakawa, H.; Nakagawa, T.; Kaneko, S. Activation of mitochondrial transient receptor potential vanilloid 1 channel contributes to microglial migration. Glia 2015, 63, 1870-1882. [CrossRef] 
50. Yocum, G.T.; Chen, J.; Choi, C.H.; Townsend, E.A.; Zhang, Y.; Xu, D.; Fu, X.W.; Sanderson, M.J.; Emala, C.W. Role of transient receptor potential vanilloid 1 in the modulation of airway smooth muscle tone and calcium handling. Am. J. Physiol. Lung Cell. Mol. Physiol. 2017, 312, L812-L821. [CrossRef]

51. Hurt, C.M.; Lu, Y.; Stary, C.M.; Piplani, H.; Small, B.A.; Urban, T.J.; Qvit, N.; Gross, G.J.; Mochly-Rosen, D.; Gross, E.R. Transient Receptor Potential Vanilloid 1 Regulates Mitochondrial Membrane Potential and Myocardial Reperfusion Injury. J. Am. Heart Assoc. 2016, 5, e003774. [CrossRef]

52. Olah, Z.; Karai, L.; Iadarola, M.J. Anandamide activates vanilloid receptor 1 (VR1) at acidic pH in dorsal root ganglia neurons and cells ectopically expressing VR1. J. Biol. Chem. 2001, 276, 31163-31170. [CrossRef]

53. Cheng, W.; Yang, F.; Takanishi, C.L.; Zheng, J. Thermosensitive TRPV channel subunits coassemble into heteromeric channels with intermediate conductance and gating properties. J. Gen. Physiol. 2007, 129, 191-207. [CrossRef]

54. Sun, Z.; Han, J.; Zhao, W.; Zhang, Y.; Wang, S.; Ye, L.; Liu, T.; Zheng, L. TRPV1 activation exacerbates hypoxia/reoxygenation-induced apoptosis in $\mathrm{H} 9 \mathrm{C} 2$ cells via calcium overload and mitochondrial dysfunction. Int. J. Mol. Sci. 2014, 15, 18362-18380. [CrossRef]

55. Faussone-Pellegrini, M.S.; Taddei, A.; Bizzoco, E.; Lazzeri, M.; Vannucchi, M.G.; Bechi, P. Distribution of the vanilloid (capsaicin) receptor type 1 in the human stomach. Histochem. Cell Biol. 2005, 124, 61-68. [CrossRef]

56. Wen, W.; Que, K.; Zang, C.; Wen, J.; Sun, G.; Zhao, Z.; Li, Y. Expression and distribution of three transient receptor potential vanilloid(TRPV) channel proteins in human odontoblast-like cells. J. Mol. Histol. 2017, 48, 367-377. [CrossRef] [PubMed]

57. Otto, M.; Bucher, C.; Liu, W.; Müller, M.; Schmidt, T.; Kardell, M.; Driessen, M.N.; Rossaint, J.; Gross, E.R.; Wagner, N.M. 12(S)-HETE mediates diabetes-induced endothelial dysfunction by activating intracellular endothelial cell TRPV1. J. Clin. Investig. 2020, 130, 4999-5010. [CrossRef] [PubMed]

58. Wisnoskey, B.J.; Sinkins, W.G.; Schilling, W.P. Activation of vanilloid receptor type I in the endoplasmic reticulum fails to activate store-operated Ca2+ entry. Biochem. J. 2003, 372, 517-528. [CrossRef]

59. Lotteau, S.; Ducreux, S.; Romestaing, C.; Legrand, C.; Van Coppenolle, F. Characterization of functional TRPV1 channels in the sarcoplasmic reticulum of mouse skeletal muscle. PLoS ONE 2013, 8, e58673. [CrossRef]

60. Xin, H.; Tanaka, H.; Yamaguchi, M.; Takemori, S.; Nakamura, A.; Kohama, K. Vanilloid receptor expressed in the sarcoplasmic reticulum of rat skeletal muscle. Biochem. Biophys. Res. Commun. 2005, 332, 756-762. [CrossRef]

61. Lozano, C.; Córdova, C.; Marchant, I.; Zúñiga, R.; Ochova, P.; Ramírez-Barrantes, R.; González-Arriagada, W.A.; Rodriguez, B.; Olivero, P. Intracellular aggregated TRPV1 is associated with lower survival in breast cancer patients. Breast Cancer (Dove Med. Press) 2018, 10, 161-168. [CrossRef]

62. Lang, H.; Li, Q.; Yu, H.; Li, P.; Lu, Z.; Xiong, S.; Yang, T.; Zhao, Y.; Huang, X.; Gao, P.; et al. Activation of TRPV1 attenuates high salt-induced cardiac hypertrophy through improvement of mitochondrial function. Br. J. Pharmacol. 2015, 172, 5548-5558. [CrossRef]

63. Jung, J.; Shin, J.S.; Lee, S.Y.; Hwang, S.W.; Koo, J.; Cho, H.; Oh, U. Phosphorylation of vanilloid receptor 1 by $\mathrm{Ca} 2+/$ calmodulin-dependent kinase II regulates its vanilloid binding. J. Biol. Chem. 2004, 279, 7048-7054. [CrossRef]

64. Xiong, S.; Wang, P.; Ma, L.; Gao, P.; Gong, L.; Li, L.; Li, Q.; Sun, F.; Zhou, X.; He, H.; et al. Ameliorating Endothelial Mitochondrial Dysfunction Restores Coronary Function via Transient Receptor Potential Vanilloid 1-Mediated Protein Kinase A/Uncoupling Protein 2 Pathway. Hypertension 2016, 67, 451-460. [CrossRef]

65. Tessier, N.; Chouabe, C.; Crola Da Silva, C.; Bonvallet, R.; Ovize, M.; Ducreux, S.; Van Coppenolle, F. Cardioprotective Role of Transient Receptor Potential Vanilloid 1 (TRPV1) Channels in H9C2 Cell Line. Arch. Cardiovasc. Dis. Suppl 2018, 10, 186.

66. Ristoiu, V.; Shibasaki, K.; Uchida, K.; Zhou, Y.; Ton, B.H.; Flonta, M.L.; Tominaga, M. Hypoxia-induced sensitization of transient receptor potential vanilloid 1 involves activation of hypoxia-inducible factor-1 alpha and PKC. Pain 2011, 152, 936-945. [CrossRef]

67. Mabalirajan, U.; Rehman, R.; Ahmad, T.; Kumar, S.; Singh, S.; Leishangthem, G.D.; Aich, J.; Kumar, M.; Khanna, K.; Singh, V.P.; et al. Linoleic acid metabolite drives severe asthma by causing airway epithelial injury. Sci. Rep. 2013, 3, 1349. [CrossRef] [PubMed]

68. Shin, C.Y.; Shin, J.; Kim, B.M.; Wang, M.H.; Jang, J.H.; Surh, Y.J.; Oh, U. Essential role of mitochondrial permeability transition in vanilloid receptor 1-dependent cell death of sensory neurons. Mol. Cell. Neurosci. 2003, 24, 57-68. [CrossRef] [PubMed] 
69. Stueber, T.; Eberhardt, M.J.; Caspi, Y.; Lev, S.; Binshtok, A.; Leffler, A. Differential cytotoxicity and intracellular calcium-signalling following activation of the calcium-permeable ion channels TRPV1 and TRPA1. Cell Calcium 2017, 68, 34-44. [CrossRef]

70. Giorgi, C.; Marchi, S.; Pinton, P. The machineries, regulation and cellular functions of mitochondrial calcium. Nat. Rev. Mol. Cell Biol. 2018, 19, 713-730. [CrossRef]

71. Flatters, S.J. The contribution of mitochondria to sensory processing and pain. Prog. Mol. Biol. Transl. Sci. 2015, 131, 119-146. [CrossRef]

72. ̈̈zdemir, Ü.S.; Nazıroğlu, M.; Şenol, N.; Ghazizadeh, V. Hypericum perforatum Attenuates Spinal Cord Injury-Induced Oxidative Stress and Apoptosis in the Dorsal Root Ganglion of Rats: Involvement of TRPM2 and TRPV1 Channels. Mol. Neurobiol. 2016, 53, 3540-3551. [CrossRef]

73. Ramírez-Barrantes, R.; Córdova, C.; Gatica, S.; Rodriguez, B.; Lozano, C.; Marchant, I.; Echeverria, C.; Simon, F.; Olivero, P. Transient Receptor Potential Vanilloid 1 Expression Mediates Capsaicin-Induced Cell Death. Front. Physiol. 2018, 9, 682. [CrossRef]

74. Kim, S.R.; Lee, D.Y.; Chung, E.S.; Oh, U.T.; Kim, S.U.; Jin, B.K. Transient receptor potential vanilloid subtype 1 mediates cell death of mesencephalic dopaminergic neurons in vivo and in vitro. J. Neurosci. 2005, 25, 662-671. [CrossRef]

75. Davies, J.W.; Hainsworth, A.H.; Guerin, C.J.; Lambert, D.G. Pharmacology of capsaicin-, anandamide-, and N-arachidonoyl-dopamine-evoked cell death in a homogeneous transient receptor potential vanilloid subtype 1 receptor population. Br. J. Anaesth. 2010, 104, 596-602. [CrossRef]

76. Chiang, H.; Ohno, N.; Hsieh, Y.L.; Mahad, D.J.; Kikuchi, S.; Komuro, H.; Hsieh, S.T.; Trapp, B.D. Mitochondrial fission augments capsaicin-induced axonal degeneration. Acta Neuropathol. 2015, 129, 81-96. [CrossRef]

77. Dedov, V.N.; Roufogalis, B.D. Mitochondrial calcium accumulation following activation of vanilloid (VR1) receptors by capsaicin in dorsal root ganglion neurons. Neuroscience 2000, 95, 183-188. [CrossRef]

78. Nita, I.I.; Caspi, Y.; Gudes, S.; Fishman, D.; Lev, S.; Hersfinkel, M.; Sekler, I.; Binshtok, A.M. Privileged crosstalk between TRPV1 channels and mitochondrial calcium shuttling machinery controls nociception. Biochim. Et Biophys. Acta 2016, 1863, 2868-2880. [CrossRef]

79. Medvedeva, Y.V.; Kim, M.S.; Usachev, Y.M. Mechanisms of prolonged presynaptic $\mathrm{Ca}^{2+}$ signaling and glutamate release induced by TRPV1 activation in rat sensory neurons. J. Neurosci. 2008, 28, 5295-5311. [CrossRef]

80. Shutov, L.P.; Kim, M.S.; Houlihan, P.R.; Medvedeva, Y.V.; Usachev, Y.M. Mitochondria and plasma membrane $\mathrm{Ca} 2+-A T P a s e$ control presynaptic Ca2+ clearance in capsaicin-sensitive rat sensory neurons. J. Physiol. 2013, 591, 2443-2462. [CrossRef]

81. Ortiz-Renteria, M.; Juarez-Contreras, R.; Gonzalez-Ramirez, R.; Islas, L.D.; Sierra-Ramirez, F.; Llorente, I.; Simon, S.A.; Hiriart, M.; Rosenbaum, T.; Morales-Lazaro, S.L. TRPV1 channels and the progesterone receptor Sig-1R interact to regulate pain. Proc. Natl. Acad. Sci. USA 2018, 115, E1657-E1666. [CrossRef]

82. Hayashi, T.; Su, T.P. Sigma-1 receptor chaperones at the ER-mitochondrion interface regulate $\mathrm{Ca}(2+)$ signaling and cell survival. Cell 2007, 131, 596-610. [CrossRef]

Publisher's Note: MDPI stays neutral with regard to jurisdictional claims in published maps and institutional affiliations.

(C) 2020 by the authors. Licensee MDPI, Basel, Switzerland. This article is an open access article distributed under the terms and conditions of the Creative Commons Attribution (CC BY) license (http://creativecommons.org/licenses/by/4.0/). 